\title{
CLINICAL IMPACT AND PROGNOSTIC VALUE OF TUMOR INFILTRATING LYMPHOCYTES IN ESOPHAGEAL SQUAMOUS CELL CARCINOMA
}

\section{Ms. Nikitha Uma Baskaran}

\author{
MBBS Department of Pathology.
}

\section{Dr. Arthi M *}

Dr. Swaminathan

\section{Rajendiran}

ABSTRACT Background: Esophageal Squamous cell carcinoma is the most prevalent type of Esophageal cancer in the world. The presence of Tumour infiltrating lymphocytes indicates a good prognosis of the cancer and this may suggest a good response to immunotherapy. Numerous immunological inhibitors have been developed to treat $a$ variety of cancers; however, the role of Tumour Infiltrating Lymphocytes in Esophageal Squamous Cell Carcinoma has not been substantiated with proper evidence. Methodology: The study enrolled 27 patients of Esophageal Squamous Cell Carcinoma between the years 2014-2019. The evaluation was based on the criteria laid down by the International Tumour Infiltrating Lymphocytes Working Group 2014 and scoring of the same was done in 400x field and were reported. Results: A total of 27 cases were studied, of which 17 were males and 10 were females. The commonest age group was $60-70$ years. 22 cases had tumours sized between $3-7 \mathrm{~cm}$. Tumour grading of pTl was seen in 1 case, grading of pT2 in 10 cases and pT3 in 16 cases. Tumour Infiltrating Lymphocytes were scored based on the standard scoring system, and the results showed that 3 cases were of Score 0, 14 cases of Score 1, 4 cases of Score 2, and 6 cases of Score 3. Conclusion: The commonest score of 1 was seen in $51.8 \%$ of the cases and that of score 3 was seen in $22.22 \%$ of the cases. Tumour Infiltrating Lymphocytes can hence serve as a predictor for good prognosis of Esophageal Squamous Cell Carcinoma following surgery or radiotherapy/chemotherapy.

KEYWORDS : Tumor Infiltrating Lymphocytes, Tumor immunomarker, Esophageal Squamous Cell Carcinoma, Prognosis

\section{INTRODUCTION:}

Esophageal carcinoma refers to malignancies associated with the esophagus, that runs from the pharynx to the stomach (1). It is the sixth most common cause of death due to cancer worldwide (2). Esophageal carcinoma can be subcategorized into two main sub-types, namely, Esophageal Squamous Cell Carcinoma (ESCC) and Esophageal Adenocarcinoma (EAC) (1).

Esophageal Squamous Cell Carcinoma arises from the epithelial cells of the esophagus (3). It is one of the malignancies associated with poor prognosis, mainly due to delay in diagnosis as well as its tendency to metastasize (4). The commonest age of onset is over 60 and is more frequently seen in males (1). The most attributing etiological factors seem to be cigarette smoking and alcohol abuse, frequent consumption of hot drinks, not having a proper nutritious diet, and chewing of betel nut $(5,6)$. There is an evident inclination of ESCC to other disorders of the esophagus, such as idiopathic achalasia, where patients with achalasia have an increased risk, as much as 50 times, of developing ESCC than the general population (7).

Suspicion of ESCC usually arises based on the symptoms presented by the patient, such as dysphagia, loss of weight, odynophagia, cough, hoarseness of voice and chest pain; along with the age and sex of the patient (8). The diagnosis of ESCC is solely based on endoscopy and biopsy (9).

Treatment of ESCC is based on age of the patient, stage of the tumor, location of the lesion, presence of other co-morbidities in the patient, as well as individual choices (9). Endoscopic, surgical resection as well as chemoradiation have helped in the reduction of the mortality rate associated with ESCC (10).

Tumour infiltrating lymphocytes (TILs) are immune cells (T cells and B cells) that migrate towards tumors and are implicated in killing them (11). They are found floating around the tumor cells without actually penetrating them. Their abundance depends on the type and stage of the tumor (12, 13). A higher number of TILs in a tumor, specifically CD3+ T cells, indicates better survival in patients with ESCC (14) (15). ESCC is often associated with loco regional recurrence and extensive metastasis which leads to poor prognosis with a five-year survival rate of about $15 \%$ (16). Hence, there is a dire need to study the various immunological inhibitors of the disease, such as TILs, that could serve as prognostic factors as well.

\section{MATERIALS AND METHODS:}

In this study, data were collected between the years 2014 and 2019 in the Department of Pathology in Sri Ramachandra Institute of Higher Education and Research. A total of 27 cases were studied.

The evaluation was based on the criteria laid down by the International Tumour Infiltrating Lymphocytes Working Group 2014 (17). It is believed that this standardized scoring system could be a universal guideline for research involving the role of TILs in various cancers and could be integrated into routine diagnostic modalities in the future $(18,19,20)$.

\section{TABLE 1: GUIDELINE FOR TIL SCORING}

1. TILs should be evaluated within the borders of the invasive tumour.

2. TILs should be reported for the stromal compartment in the area occupied by mononuclear inflammatory cells over total intra-tumoral stromal area.

3. Exclude TILs outside of the tumour border.

4. Exclude TILs in tumour zones with crush artifacts, necrosis and areas of hyalinization.

5. All mononuclear cells (including lymphocytes and plasma cells) should be scored, but polymorphonuclear leukocytes are excluded. 
6. Full sections are preferred over biopsies whenever possible. One section $(4-5 \mu \mathrm{m}$, magnification $\times 200-400)$ per patient is currently considered to be sufficient.

7. The percentage of stromal TILs is a semi-quantitative parameter for this assessment, for example, $80 \%$ stromal TILs means that $80 \%$ of the stromal area shows a dense mononuclear infiltrate.

The scoring of lymphocytes was done in $400 x$ field as follows:

Score 0-No infiltrating lymphocytes were seen

Score 1- Mild increase in infiltrating lymphocytes observed in the tumor nest or stroma

Score 2- Increase in infiltrating lymphocytes interwoven with the tumor tissue

Score 3-Prominent infiltrating lymphocytes seen incorporated in the tumor tissue.

\section{RESULTS}

27 patients were studied, of which 17 were males (63\%) and 10 were females (37\%). The commonest age group was 60-70 years ( 12 cases- $44.4 \%$ ). 22 cases had tumors sized between $3-$ $7 \mathrm{~cm}(81.4 \%)$. Tumour stage of $\mathrm{pTl}$ was seen in 1 case $(0.03 \%)$, pT2 was seen in 10 cases $(37.03 \%)$ and pT3 in 16 cases $(59.25 \%)$. The tumor was commonly seen in the distal esophagus of the specimen obtained from esophagectomy.

TILs were then assessed using H\&E slides of the specimens mentioned above and scored based on the standard scoring system (Image 1). The results showed the $11.11 \%$ of the cases were of score 0 with no infiltrating lymphocytes, $51.8 \%$ were of score 1 with a few lymphocytes seen in the tumor nest or stroma, $14.8 \%$ were of score 2 with lymphocytes interwoven with the tumor tissues and $22.22 \%$ were of score 3 with high numbers of lymphocytes incorporated into the tumor tissues.

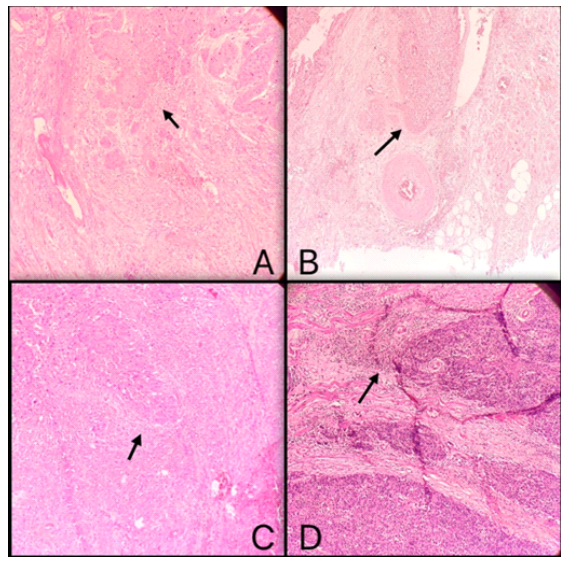

IMAGE 1: H\&E slides in 200X magnification (A- Score 0, BScore 1, C-Score 2, D-Score 3)

\section{DISCUSSION:}

Specimens of esophageal carcinoma were obtained and H\&E slides were prepared and TILs were analyzed and scored to see if they can provide a prognostic tool for ESCC. Statistical analysis according to Cramer's $\mathrm{V}$ technique was done to find the correlation between the two variables, which was based on the Chi-square exact test that helped assess the independence between the two variables (21).

This study incorporated 27 patients, with a male predominance of 17 cases, which was in concordance to the results that were obtained by Chu Y, Liao J, Li J, et al (22), which further advocates that males have a higher incidence of developing ESCC (1).

The mean age seen in this study was the age group of 60-70, that is similar to the epidemiological studies reported by
Jiang, D. et al, where the mean age was 62 (37-83 years) within a sample size of 235 (23). This is in concordance with the fact that ESCC occurs in patients over the age of 60 (1).

The tumor grading that was commonly seen was pT3 in 16 out of the 27 cases, which was comparable to the findings seen by Chen K, Zhu Z, Zhang N, et al, where stage 3 tumor (scored according to the 7th IUCC/AJCC staging system) was prominently seen in 273 out of 536 patients (50.9\%) (24), which further confirms that ESCC is usually asymptomatic in the early stages and is only diagnosed at later stages.

A high TIL score was mainly seen in males in comparison to females, which was in accordance with the results reported by $\mathrm{Chu} \mathrm{Y}, \mathrm{Liao} \mathrm{J}, \mathrm{Li} \mathrm{J}$, et al (22). However, this finding is contrary to that laid out by Noble F, Mellows T, McCormick Matthews LH, et al, that showed a female predominance in the presence of higher score TILs in Esophageal Adenocarcinoma (25).

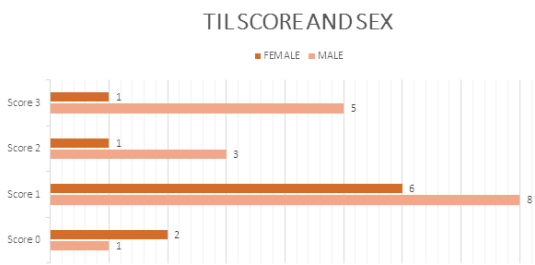

\section{IMAGE 2: COMPARISON BETWEEN TIL SCORE AND SEX}

The correlation between TIL SCORE AND SEX is $0.313 \mathrm{P}$ value is 0.448

Furthermore, in TIL Score 1,2 and 3, the odds of a patient being male is high. This observation is tabulated in Table 2.

TABLE 2: ODDS RATIO FOR TIL SCORE AND SEX

\begin{tabular}{|c|c|c|c|c|}
\hline $\begin{array}{c}\text { TIL } \\
\text { SCORE }\end{array}$ & MALE & FEMALE & $\begin{array}{c}\text { ODDS FOR } \\
\text { MALE }\end{array}$ & $\begin{array}{c}\text { ODDS FOR } \\
\text { FEMALE }\end{array}$ \\
\hline 0 & 1 & 2 & 0.5 & 2 \\
\hline 1 & 8 & 6 & 1.333333333 & 0.75 \\
\hline 2 & 3 & 1 & 3 & 0.33333333 \\
\hline 3 & 5 & 1 & 5 & 0.2 \\
\hline
\end{tabular}

Additionally, on comparing the TIL score with the stage of the tumour, it was observed that a TIL score of 3 was mainly seen in T3 stage of the tumour, which tells us that higher grade tumours have higher concentration of TILs. This finding was in concordance to the results reported by Chu Y, Liao J, Li J, et al (22).

TILSCOREANDSTAGEOFTUMOR

-

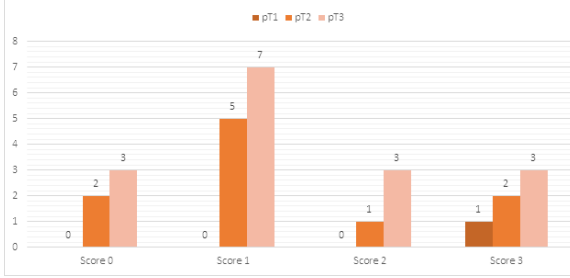

IMAGE 3: COMPARISON BETWEEN TIL SCORE AND STAGE OF TUMOR

The correlation between TIL SCORE AND STAGE OF TUMOR is 0.272

\section{Pvalue is 0.674}

On comparing the TIL score with the age of the patients, this study showed that a high TIL score of 3 was seen in 6 cases belonging to the age group of 51-70. This was in accordance with the results reported by Chu Y, Liao J, Li J, et al (22). 
TILSCOREAND AGEGROUP

- Score 0 - Score 1 - $\operatorname{score} 2$ in Score 3

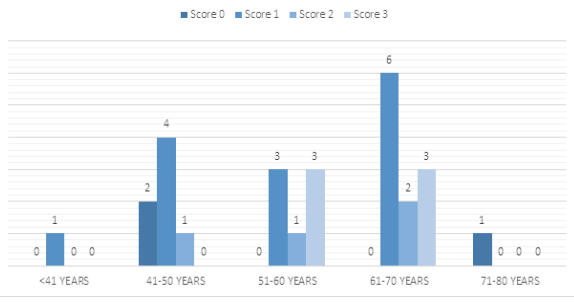

IMAGE 4: COMPARISON BETWEEN TIL SCORE AND AGE GROUP

\section{The correlation between TIL SCORE AND AGE GROUP is 0.446}

\section{Pvalue is 0.185}

Since the P-value is greater than 0.05 in all the parameters, there is no significant relationship between TIL Score and Sex, Age group and Tumor Stage. This could probably be due to the small sample size of 27 patients.

Furthermore, studies show that generalized infiltration of TILs in an entire tumor mass shows a better clinical outcome compared to those with minimal or no infiltrating lymphocytes. This observation was seen in the hypothesis laid down by Hendry S, Salgado R, Gevaert T, et al, that stated that dense lymphocytic infiltration correlates with better clinical outcomes in breast carcinoma (26). Moreover, the location and extent of infiltration play an important role in determining the prognostic value of TILs in solid tumors (4). A study by Yu X, Zhang Z, Wang Z, Wu P, Qiu F, Huang J, showed that analyzing the spatial orientation of the TILs in a tumor mass would further help understand the predictive value of TILs as prognostic biomarkers in breast cancer (27). Furthermore, various subpopulations of TILs and their local density in a primary tumor would also affect the analysis of these immune cells as a prognostic biomarker (28). Studies by Matsutani S, Shibutani M, Maeda K, et al and Hao J, Li M, Zhang T, et al, suggest that the density of TILs, irrespective of their location, does not confer to a better prognosis of patients with ESCC $(29,30)$. This could have been due to different methodologies of conducting the experiment. Hence, understanding the mechanism of action of these TILs with the tumor cells is vital.

\section{CONCLUSION:}

TILs can be used as a prognostic factor to evaluate better clinical outcome in patients with ESCC in the future with a better understanding of their mode of action, in addition to analyzing more studies using homogenous groups of patients having similar tumor details like size, location, and stage, along with comparable treatment modalities.

\section{ACKNOWLEDGEMENTS:}

I would like to sincerely thank Ms. Anjana K, M. Sc Statistics, Sri Ramachandra Institute of Higher Education and Research, Chennai, for helping with the statistical analysis of the data collected for this research.

\section{FOOTNOTE:}

\section{CONFLICTS OF INTEREST:}

Conflicts of Interest: All authors have completed the ICMJE uniform disclosure form. The authors have no conflicts of interest to declare.

\section{ETHICALL STATEMENT:}

Ethical clearance for this research was obtained (REF: CSP/20/AUG/COVID/02) from the 'ETHICS COMMITTEE FOR STUDENTS PROJECTS' of Sri Ramachandra Institute of Higher Education and Research, Chennai, India.

\section{REFERENCES:}

(1) Montgomery, EA; et al. (2014). "Oesophageal Cancer". In Stewart, BW; Wild CP (eds.). World Cancer Report 2014. World Health Organization. pp. 528-543. ISBN 978-9283204299

(2) Chen W, Zheng R, Baade PD, et al. Cancer statistics in China, 2015. Cancer J Clin. 2016;66(2):115-32.

(3) Kelsen, David (2007). Gastrointestinal oncology: principles and practices (2nd ed.). Philadelphia, Pa.: Lippincott Williams \& Wilkins. p. 4. ISBN 9780781776172.

(4) Hao J, Li M, Zhang T, Yu H, Liu Y, Xue Y, An R, Wang S. Prognostic Value of Tumour-Infiltrating Lymphocytes Differs Depending on Lymphocyte Subsets in Esophageal Squamous Cell Carcinoma: An Updated Meta-Analysis. Front Oncol. 2020 Apr 28; 10:614.

(5) Zhang, HZ; Jin, GF; Shen, HB (Jun 2012). "Epidemiologic differences in esophageal cancer between Asian and Western populations". Chinese Journal of Cancer. 31 (6): 281-6.

(6) Pennathur A, Gibson MK, Jobe BA, Luketich JD (February 2013). "Oesophageal carcinoma". Lancet. 381 (9864): 400-12.

(7) Torres-Aguilera M, Remes Troche JM. Achalasia and esophageal cancer: risks and links. Clin Exp Gastroenterol. 2018 Sep 6; 11:309-316.

(8) Ferri, FF, ed. (2012). "Tumors". Ferri's clinical advisor 2013. Philadelphia, PA: Mosby (Elsevier). pp. 389-391. ISBN 978-0323083737.

(9) Stahl, M; Mariette, C; Haustermans, K; Cervantes, A; Arnold, D; ESMO Guidelines Working, Group (Oct 2013). "Oesophageal cancer: ESMO Clinical Practice Guidelines for diagnosis, treatment and follow-up". Annals of Oncology. 24 Suppl 6: vi5l-6

(10) Reichenbach ZW, Murray MG, Saxena R, Farkas D, Karassik EG, Klochkova A, Patel K, Tice C, Hall TM, Gang J, Parkman HP, Ward SJ, Tétreault MP, Whelan KA Adv Cancer Res. 2019; 144():95-135.

(11) Vánky F, Klein E, Willems J, Böök K, Ivert T, Péterffy A, Nilsonne U, Kreicbergs A, Aparisi T (1986). "Lysis of autologous tumour cells by blood lymphocytes tested at the time of surgery. Correlation with the postsurgical clinical course". Cancer Immunology, Immunotherapy. 21 (1): 69-76.

(12) Teixeira, Luis; Rothé, Françoise; Ignatiadis, Michail; Sotiriou, Christos (2016). "Breast Cancer Immunology". Oncology Times. 38 (9): 18-19.

(13) Schumacher K, Haensch W, Roefzaad C, Schlag PM. Prognostic significance of activated $\mathrm{Cd} 8(+) \mathrm{T}$ cell infiltrations within esophageal carcinomas. Cancer Res. 2001;61(10):3932-36.

(14) Cho Y, Miyamoto M, Kato K, et al. CD4+ and CD8+ T cells cooperate to improve prognosis of patients with esophageal squamous cell carcinoma. Cancer Res. 2003;63(7):1555-59. "SEER Stat Fact Sheets: Esophageal Cancer"

(15) .National Cancer Institute. Archived from the original on 6 July 2014. Retrieved 18June 2014

(16) Salgado R, Denkert C, Demaria S, Sirtaine N, Klauschen F, Pruneri G, Wienert S, Van den Eynden G, Baehner FL, Penault-Llorca F, Perez EA, Thompson EA, Symmans WF, Richardson AL, Brock J, Criscitiello C, Bailey H, Ignatiadis M Floris G, Sparano J, Kos Z, Nielsen T, Rimm DL، Allison KH, Reis-Filho JS, Loibl S, Sotiriou C, Viale G, Badve S, Adams S, Willard-Gallo K, Loi S, International TILs Working Group 2014. Ann Oncol. 2015 Feb; 26(2):259-71.

(17) Galon J, Mlecnik B, Bindea G, Angell HK, Berger A, Lagorce C, Lugli A, Zlobec I, Hartmann A, Bifulco C, Nagtegaal ID, Palmqvist R, Masucci GV, Botti G, Tatangelo F, Delrio P, Maio M, Laghi L, Grizzi F, Asslaber M, D'Arrigo C, VidalVanaclocha F, Zavadova E, Chouchane L, Ohashi PS, Hafezi-Bakhtiari S, Wouters BG, Roehrl M, Nguyen L, Kawakami Y, Hazama S, Okuno K, Ogino S, Gibbs P, Waring P, Sato N, Torigoe T, Itoh K, Patel PS, Shukla SN, Wang Y, Kopetz S, Sinicrope FA, Scripcariu V, Ascierto PA, Marincola FM, Fox BA, Pagès $F$

(18) JPathol. 2014 Jan; 232(2):199-209.

(19) Donnem T, Kilvaer TK, Andersen S, Richardsen E, Paulsen EE, Hald SM, AlSaad S, Brustugun OT, Helland A, Lund-Iversen M, Solberg S, Gronberg BH, Wahl SG, Helgeland L, Fløtten O, Pohl M, Al-Shibli K, Sandanger TM Pezzella F, Busund LT, Bremnes RM

(20) Ann Oncol. 2016 Feb; 27(2):225-32

(21) Cramér, Harald. 1946. Mathematical Methods of Statistics. Princeton: Princeton University Press, page 282 (Chapter 21. The two-dimensional case). ISBN 0-691-08004-6.

(22) Chu Y, Liao J, Li J, Wang Y, Yu X, Wang J, Xu X, Xu L, Zheng L, Xu J, Li L. CD103+ tumor-infiltrating lymphocytes predict favorable prognosis in patients with esophageal squamous cell carcinoma. J Cancer. 2019 Aug 28;10(21):52345243 .

(23) Jiang, D. et al. Tumour infiltrating lymphocytes correlate with improved survival in patients with esophageal squamous cell carcinoma. Sci. Rep. 7 44823

(24) Chen K, Zhu Z, Zhang N, Cheng G, Zhang F, Jin J, Wu J, Ying L, Mao W, Su D. Tumor-Infiltrating CD4+ Lymphocytes Predict a Favorable Survival in Patients with Operable Esophageal Squamous Cell Carcinoma. Med Sci Monit. 2017 Sep 26; 23:4619-4632.

(25) Noble F Mellows T, McCormick Matthews LH, Bateman AC, Harris S, Underwood TJ, Byrne JP, Bailey IS, Sharland DM, Kelly JJ, Primrose JN, Sahota SS, Bateman AR, Thomas GJ, Ottensmeier CH. Tumour infiltrating lymphocytes correlate with improved survival in patients with oesophageal adenocarcinoma. Cancer Immunol Immunother. 2016 Jun;65(6):651-62.

(26) Hendry S, Salgado R, Gevaert T, Russell PA, John T, Thapa B, Christie M, van de Vijver K, Estrada MV, Gonzalez-Ericsson PI, Sanders M, Solomon B, Solinas C, Van den Eynden GGGM, Allory Y, Preusser M, Hainfellner J, Pruner G, Vingiani A, Demaria S, Symmans F, Nuciforo P, Comerma L, Thompson EA, Lakhani S, Kim SR, Schnitt S, Colpaert C, Sotiriou C, Scherer SJ, Ignatiadis M, Badve S, Pierce RH, Viale G, Sirtaine N, Penault-Llorca F, Sugie T, Fineberg S, Paik S, Srinivasan A, Richardson A, Wang Y, Chmielik E, Brock J, Johnson DB, Balko J, Wienert S, Bossuyt V, Michiels S, Ternes N, Burchardi N, Luen SJ Savas P, Klauschen F, Watson PH, Nelson BH, Criscitiello C, O'Toole S, Larsimont $D$, de Wind R, Curigliano G, André F, Lacroix-Triki M, van de Vijver M, Rojo F, Floris G, Bedri S, Sparano J, Rimm D, Nielsen T, Kos Z, Hewitt S, Singh B, Farshid G, Loibl S, Allison KH, Tung N, Adams S, Willard-Gallo K, Horlings HM, Gandhi L, Moreira A, Hirsch F, Dieci MV, Urbanowicz M, Brcic I 
Korski K, Gaire F, Koeppen H, Lo A, Giltnane J, Rebelatto MC, Steele KE, Zha J, Emancipator K, Juco JW, Denkert C, Reis-Filho J, Loi S, Fox SB. Assessing Tumor-infiltrating Lymphocytes in Solid Tumors: A Practical Review for Pathologists and Proposal for a Standardized Method From the International Immunooncology Biomarkers Working Group: Part 1: Assessing the Host Immune Response, TILs in Invasive Breast Carcinoma and Ductal Carcinoma In Situ, Metastatic Tumor Deposits and Areas for Further Research. Adv Anat Pathol. 2017 Sep;24(5):235-251.

(27) Yu X, Zhang Z, Wang Z, Wu P, Qiu F, Huang J. Prognostic and predictive value of tumor-infiltrating lymphocytes in breast cancer: a systematic review and meta-analysis. Clin Transl Oncol. (2016) 18:497-506. 10.1007/s12094-0151391-y

(28) Peled M Onn A Herbst RS. Tumor-Infiltrating Lymphocytes-Location for Prognostic Evaluation. Clin Cancer Res. (2019) 25:1449-51. 10.1158/10780432.CCR-18-3803

(29) Matsutani S, Shibutani M, Maeda K, Nagahara H, Fukuoka T, Nakao S, et al. Significance of tumor-infiltrating lymphocytes before and after neoadjuvant therapy for rectal cancer. Cancer Sci. (2018) 109:966-79. 10.1111/cas.13542

(30) Yasunaga M, Tabira Y, Nakano K, Iida S, Ichimaru N, Nagamoto N, et al. Accelerated growth signals and low tumor-infiltrating lymphocyte levels predict poor outcome in T4 esophageal squamous cell carcinoma. Ann Thorac Surg. (2000) 70:1634-40. 10.1016/S0003-4975(00)01915-9 